\title{
Anxiety in Male Professionals Working from Home in India During Lockdown Due to Corona Pandemic in 2020 - A Cross Sectional Study
}

\author{
Abhinit Kumar'1, Kunal Kumar², Nikhil Nayar³, Shubhika Aggarwal ${ }^{4}$ \\ 1,2,3,4 Department of Psychiatry, School of Medical Sciences and Research, Sharda Hospital, \\ Greater Noida, Uttar Pradesh, India.
}

\section{ABSTRACT}

\section{BACKGROUND}

Mental health contributes towards a healthy life to a larger extent in every individual. Besides physical health, this devastating Coronavirus disease - 19 (COVID-19) pandemic had an impact on mental health. The purpose of this study was to bring the impact of COVID-19 pandemic on male professionals who were working from their home during the lockdown and also their anxiety levels. Also this study will highlight the effect of the lockdown on their professional, financial, and personal life.

\section{METHODS}

Online questionnaire designed for survey using Qualtrics software and BAI scale (Beck Anxiety Inventory) was used to assess the anxiety level in male professionals working from home.

\section{RESULTS}

$41 \%$ of male professionals (54 professionals out of 132) showed moderate to severe anxiety levels due to social and physical restrictions during the COVID-19 pandemic lockdown.

\section{CONCLUSIONS}

The finding of anxiety levels in persons working from home after using BAI indicates the role of COVID-19 pandemic lockdown. Professional, financial and personal life of professionals was also affected during this period. It highlights the role \& importance of a healthy work culture, maintaining balance between personal and professional life. The policy makers should provide interventions to mitigate the effect of working from home (WFH). It also emphasizes the role of employers to promote and provide good mental health at all working spaces, flexible working hours and also to sensitize and counsel mental health professionals to seek intervention.

\section{KEY WORDS}

COVID-19, Corona Virus, Anxiety, WFH, Professional.
Corresponding Author: Dr. Shubhika Aggarwal, SMS \& R, Sharda Hospital, Block-A, $2^{\text {nd }}$ Floor, Plot No. 32, 34, Knowledge Park-III, Greater Noida-201306, Uttar Pradesh, India. E-mail: shubsaggarwal@gmail.com

DOI: $10.14260 /$ jemds/2021/775

How to Cite This Article:

Kumar A, Kumar K, Nayar N, et al. Anxiety in male professionals working from home in India during lockdown due to corona pandemic in 2020 - a cross sectional study. J Evolution Med Dent Sci 2021;10(45):3832-3836, DOI: $10.14260 /$ jemds/2021/775

Submission 26-10-2021, Peer Review 05-11-2021, Acceptance 10-12-2021, Published 13-12-2021.

Copyright (C) 2021 Abhinit Kumar et al. This is an open access article distributed under Creative Commons Attribution License [Attribution 4.0 International (CC BY 4.0)] 


\section{BACKGROUND}

Pandemic created situation of uncertainty and thus everyone had feeling of helplessness and vulnerability. Public spaces, public transport and workplaces were closed to curb the spread of corona virus infection, the lockdown and closing of office spaces opened the opportunity to the professionals to work from home. The situation prolonged beyond everyone's expectations. This unprecedented experience of home quarantine under lockdown caused high prevalence of anxiety and depression as noted by an earlier Canadian study on the effects of quarantine after the severe acute respiratory syndrome (SARS) epidemic. ${ }^{1}$

The world health organization (WHO) has also expressed its concern over the pandemic's mental health and psychosocial consequences. ${ }^{2}$ The recent survey by Indian psychiatric society showed a $20 \%$ increase in mental illness since the corona virus outbreak. ${ }^{3}$ The dramatic debut of corona virus (COVID-19) on the global stage has left everyone feeling vulnerable and helpless. It originated in a wet market of Wuhan, China and then spread to infect the whole world. ${ }^{4}$ It has affected as of 15 November 60 million with 1 million deaths worldwide, whereas in India accounting to more than 9 million cases with a death toll exceeding 1.2 lakh. ${ }^{5}$ And the pandemic is increasing demand for mental health services. Bereavement, isolation, loss of income and fear are triggering mental health conditions or exacerbating existing ones. Many people may be facing increased levels of alcohol and drug use, insomnia, and anxiety. Meanwhile, COVID-19 itself can lead to neurological and mental complications, such as delirium, agitation, and stroke. People with pre-existing mental, neurological or substance use disorders are also more vulnerable to SARS-CoV-2 infection. They may stand a higher risk of severe outcomes and even death. "Good mental health is absolutely fundamental to overall health and well-being," as stated by Dr. Tedros Adhanom Ghebreyesus, Director General of the World Health Organization. He also stated that "COVID-19 has interrupted essential mental health services around the world just when they're needed the most. World leaders must move fast and decisively invest more in lifesaving mental health programmes during the pandemic and beyond." 6

In public mental health terms, the main psychological impact to date is elevated rates of stress or anxiety. But as new measures and impacts are introduced especially quarantine and its effects on many people's usual activities, routines or livelihoods levels of loneliness, depression, harmful alcohol and drug use, and self-harm or suicidal behaviour are also expected to rise. ${ }^{7}$ According to Salari N et al. it can be concluded that the COVID-19 pandemic can affect mental health in individuals and different communities. Therefore, in the current crisis, it is vital to identify individuals prone to psychological disorders from different groups and at different layers of populations, so that with appropriate psychological strategies, techniques and interventions, the general population mental health is preserved and improved. ${ }^{8}$

This present study emphasizes the need of identifying psychological wellbeing of professionals working from home to get timely intervention as well promotion of mental health.

\section{Study Objective}

1. To evaluate the severity of anxiety in male professionals working from home during the lockdown due to COVID19 pandemic.

2. Its effect on their personal, professional and financial life.

\section{METHODS}

This is a cross sectional study conducted on 132 male working professionals who were working from home because of the corona virus pandemic. The sample collected was from 01 October 2020 to 30 October 2020.

\section{Sampling Place}

Free online survey was designed using Qualtrics software, a well-accepted tool for online surveys. 9 Questionnaire was sent to working professionals who were working from home through social media platform and through emails.

\section{Tools}

1. Online survey questionnaire designed using Qualtrics software takes 5 - 10 minutes.

2. BAI (Beck Anxiety inventory) - This scale is a selfreporting scale which consists of 21 items. Reliabilityinternal consistency for the BAI (Cronbach's a $=0.92$ ) Test - retest reliability ( 1 week) for the $\mathrm{BAI}=0.75 .{ }^{10}$

\section{Scoring}

Each symptom has four possible answer choices -

- $\quad$ Not at all (score-0)

- Mildly - it did not bother me much (score-1)

- Moderately - it was very unpleasant, but I could stand it (score-2)

- Severely - I could barely stand it (score-3)

The value to each item was summed yielding on overall or total score for all symptoms that can range between 0 and 23 points. A total score of $0-7$ is interpreted as a minimal level of anxiety, 8 - 15 as mild, 16 - 25 as moderate, and $26-63$ as severe. ${ }^{11}$

\section{Inclusion Criteria}

- Age between 20-60 years.

- Professionals working from home.

- Participant completed full online survey.

\section{Exclusion Criteria}

- Age $<20$ years.

- Participant having any past or current psychiatric treatment history.

- History of any substance abuse. 


\section{Sampling Methods}

Participants were recruited by snowball sampling method and a questionnaire was designed using Qualtrics software which was sent through social media platform i.e. emails and also requested and encouraged them to forward it to their colleague and contacts who were working from home in chain referral pattern. Data was collected over a period of one month.

\section{Statistical Analysis}

Statistical Package for Social Sciences (SPSS 20) software was used for data analysis.

\section{RESULTS}

A sample of 132 male professionals working from home was included in this study to find out anxiety levels Table-1.

\begin{tabular}{|cc|}
\hline Professional Life & Male (n = 132) (\%) \\
Much worse & $6(4.55)$ \\
Somewhat worse & $81(61.36)$ \\
State the same & $21(15.91)$ \\
Much better & $0(0.0)$ \\
Much worse + Somewhat worse & $87(65.9)$ \\
Somewhat better + Much better & $21(15.9)$ \\
\hline Table 1. Effect on the Professional Life of Males Due to Work from \\
Home in the COVID-19 Pandemic
\end{tabular}

\begin{tabular}{|cc|}
\hline Financial Life & Male $(\mathbf{n}=\mathbf{1 3 2}) \mathbf{( \% )}$ \\
Much worse & $0(0.0)$ \\
Somewhat worse & $11(8.33)$ \\
State the same & $24(18.18)$ \\
Much better & $12(9.09)$ \\
Much worse + Somewhat worse & $11(8.33)$ \\
Somewhat better + Much better & $36(27.3)$ \\
\hline Table 2. Effect on the Financial Life of Males Due to Work \\
from Home in the COVID-19 Pandemic \\
\hline
\end{tabular}

The result in this study shows significant adverse effect on the professional life with 6 professionals (4.55\%) stating that their professional life was much worse during the lockdown. 81 professionals (61.36\%) reporting professional life somewhat worse and 21 individuals (15.91\%) reporting professional life was somewhat better during the lockdown. Total 87 professionals (65.9\%) reporting the worsening of professional life and 21 professionals (15.9\%) reporting better professional life while working from home during lockdown.

The financial aspect of professionals showed improvement with only 11 professionals reported somewhat worse financial life $(8.33 \%)$ as compared to a total 36 professionals $(27.3 \%)$ reporting better financial life with 24 professionals $(18.18 \%)$ reporting somewhat better financial life while 12 professionals reporting much better financial life.

The personal life was also affected with 12 professionals (9.90 \%) reporting much worse personal life, 33 professionals $(25.0 \%)$ reporting somewhat worse personal life due to working from home in COVID-19 pandemic because of lockdown as compared to 21 professionals (15.91\%) reporting somewhat better personal life and only 9 professionals $(6.82 \%)$ reporting much better personal life. Table-3.

\begin{tabular}{|cc|}
\hline Personal Life & Male (n = 132) \\
\hline Much worse (MW) & $12(9.09 \%)$ \\
Somewhat worse (SW) & $33(25.0 \%)$ \\
Somewhat better (SB) & $21(15.91 \%)$ \\
Much better (MB) & $9(6.82 \%)$ \\
Much worse + Somewhat worse & $45(34.1 \%)$ \\
Somewhat better + Much better & $30(22.7 \%)$ \\
\hline Table 3. Effect on the Personal Life of Males Due to Work \\
from Home in the COVID-19 Pandemic \\
\hline
\end{tabular}

\section{Beck Anxiety Inventory (BAI)}

The severity of anxiety level in these male professionals after applying Beck Anxiety Inventory (BAI) was $25 \%$ mild, $13.6 \%$ moderate and $2.3 \%$ severe anxiety (Total sample 132). Out of 132 professionals, 78 (59\%) professionals showed minimal anxiety level. So, $41 \%$ (54 professionals) required psychiatric intervention in the form of medicine and psychotherapy. Table-4

\begin{tabular}{|cccccc|}
\hline Gender & Minimal & Mild & Moderate & Severe & Grand Total \\
Males & $78(59 \%)$ & $33(25 \%)$ & $18(13.6 \%)$ & $3(2.3 \%)$ & 132 \\
\hline \multicolumn{5}{c}{ Table 4. Severity of Anxiety } \\
\hline
\end{tabular}

The level of moderate to severe anxiety in this study was only $4.1 \%$ if married as compared to $30 \%$ in unmarried males. In type of family, $14.7 \%$ of moderate to severe level of anxiety was seen in nuclear family and $20 \%$ in joint family. $21.9 \%$ of working professionals who had no children reported moderate to severe anxiety levels while with those who are having children, it was $0 \%$. Table- 5

\begin{tabular}{|c|c|c|c|c|c|c|c|}
\hline $\begin{array}{r}\text { A } \\
\text { Leve }\end{array}$ & $\begin{array}{l}\text { nxiety } \\
\text { el in Male }\end{array}$ & 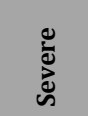 & $\begin{array}{l}\frac{\pi}{0} \\
\frac{0}{0} \\
\frac{0}{2}\end{array}$ & $\frac{\bar{T}}{\Sigma}$ & $\begin{array}{l}\overline{\text { Jै }} \\
\text { zo } \\
z\end{array}$ & 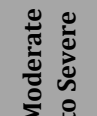 & 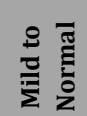 \\
\hline Marital & $\begin{array}{l}\text { Married } \\
(\mathrm{n}=72)\end{array}$ & $\begin{array}{c}3 \\
(4.1 \%)\end{array}$ & $\begin{array}{c}0 \\
(0 \%)\end{array}$ & $\begin{array}{c}15 \\
(20.8 \%)\end{array}$ & $\begin{array}{c}54 \\
(78.3 \%)\end{array}$ & $\begin{array}{c}3 \\
(4.1 \%)\end{array}$ & $\begin{array}{c}69 \\
(95.8 \%)\end{array}$ \\
\hline status & $\begin{array}{l}\text { Unmarried } \\
(\mathrm{n}=60)\end{array}$ & $\begin{array}{c}0 \\
(0 \%)\end{array}$ & $\begin{array}{c}18 \\
(30 \%)\end{array}$ & $\begin{array}{c}18 \\
(30 \%)\end{array}$ & $\begin{array}{c}24 \\
(40 \%)\end{array}$ & $\begin{array}{c}18 \\
(30 \%)\end{array}$ & $\begin{array}{c}42 \\
(70 \%)\end{array}$ \\
\hline $\begin{array}{l}\text { Type of } \\
\text { family }\end{array}$ & $\begin{array}{l}\text { Nuclear family } \\
\quad(\mathrm{n}=102)\end{array}$ & $\begin{array}{c}3 \\
(2.9 \%)\end{array}$ & $\begin{array}{c}12 \\
(11.8 \%)\end{array}$ & $\begin{array}{c}21 \\
(20.6 \%)\end{array}$ & $\begin{array}{c}66 \\
(64.7 \%)\end{array}$ & $\begin{array}{c}15 \\
(14.7 \%)\end{array}$ & $\begin{array}{c}87 \\
(85.3 \%)\end{array}$ \\
\hline & $\begin{array}{l}\text { Joint family } \\
(\mathrm{n}=30)\end{array}$ & 0 & $\begin{array}{c}6 \\
(20 \%)\end{array}$ & $\begin{array}{c}12 \\
(40 \%)\end{array}$ & $\begin{array}{c}12 \\
(40 \%)\end{array}$ & $\begin{array}{c}6 \\
(20 \%)\end{array}$ & $\begin{array}{c}24 \\
(80 \%)\end{array}$ \\
\hline $\begin{array}{c}\text { No. of } \\
\text { children }\end{array}$ & $\begin{array}{l}\text { None } \\
(\mathrm{n}=96)\end{array}$ & $\begin{array}{c}3 \\
(3.1 \%)\end{array}$ & $\begin{array}{c}18 \\
(18.6 \%)\end{array}$ & $\begin{array}{c}21 \\
(21.7 \%)\end{array}$ & $\begin{array}{c}54 \\
(56.3 \%)\end{array}$ & $\begin{array}{c}21 \\
(21.9 \%)\end{array}$ & $\begin{array}{c}75 \\
(78.1 \%)\end{array}$ \\
\hline & $\begin{array}{c}\text { One } \\
(n=21)\end{array}$ & 0 & 0 & $\begin{array}{c}3 \\
(14.7 \%)\end{array}$ & $\begin{array}{c}18 \\
(85.3 \%)\end{array}$ & 0 & $\begin{array}{c}21 \\
(100 \%)\end{array}$ \\
\hline & $\begin{array}{c}\text { Two or more } \\
(n=15)\end{array}$ & 0 & 0 & $\begin{array}{c}9 \\
(67 \%)\end{array}$ & $\begin{array}{c}6 \\
(33 \%)\end{array}$ & 0 & $\begin{array}{c}15 \\
(100 \%)\end{array}$ \\
\hline & Dituib & of & $=3 x$ & ity $L$ & $\begin{array}{l}\text { of } A r \\
c S\end{array}$ & & ling to \\
\hline
\end{tabular}

\section{DISCUSSION}

Nationwide lockdown due to COVID-19 pandemic affected not only physical health but also adversely affected the psychological wellbeing of professionals who are working from home. In this study, it was found that 87 male professionals i.e. $65.9 \%$ reported much worse to somewhat level of worsening of their professional life due to COVID-19 lockdown, this might be attributed due to poor internet connectivity at home, care giver responsibility at home and limited time to conduct normal work load. Financial situation got better in 36 male professionals out of 132 due to the lockdown which was $27.3 \%$; this might be attributed due to maintenance of salary i.e., less recreational activities, luxury 
expenses and also savings on fuel etc. Personal life of 45 professionals working from home got adversely affected during the lockdown i.e., $34.1 \%$. The levels of remotely working males severity of anxiety was not associated with the their marital status, type of family or number of children during this COVID-19 lockdown.

In the study done on female professionals working from home, the biggest fallout of WFH was blurring of working hours and personal time with expectations to be on call late into night or on weekends. Strained interpersonal relationships and domestic physical and sexual abuse were also reported even by these professionally qualified educated females in previous studies. ${ }^{12,13,14}$ According to the Microsoft latest working trend index, one third of workers in India are facing increased burn out due to lack of separation between work and personal life. ${ }^{15}$ The COVID-19 confinement could significantly increase anxiety of quarantined people. Males were more vulnerable to the quarantine of COVID-19 with significantly increased anxiety level than females.

The results suggest that attention should be paid to anxiety during a second round of quarantine due to COVID-19 and are of help in planning psychological interventions. ${ }^{16}$ The COVID-19 pandemic has disrupted or halted critical mental health services in $93 \%$ of countries worldwide while the demand for mental health is increasing, according to a new WHO survey. The survey of 130 countries provides the first global data showing devastating impact of COVID-19 on access to mental health services and underscores the urgent need for increased funding. ${ }^{17}$ Anxiety when above normal weakens body's immune system and consequently increases the risk of contracting the virus.

However, psychological state changes with the passage of time and with the alterations in one's surrounding environment. Therefore, it is necessary to portray the psychological impacts of the COVID-19 catastrophe over a longer and more forward-looking period. Follow-up studies can be helpful in clarifying the mental state of the population in future. Although several research works in this metaanalysis have used the same tests for population screening, yet there were a few studies that followed different scales to assess stress, anxiety and depression. ${ }^{8}$

According to Banerjee D, a Psychiatrist can play a pivotal role and offer a balance perspective to improve the knowledge and attitude about their illness as well as addressing the generalized anxiety and apprehension regarding the COVID19 pandemic. ${ }^{18}$ During any pandemic, health care services should keep mental health at epicentre which will prevent crisis at time of pandemic but also help in containing its spread. ${ }^{18}$

\section{CONCLUSIONS}

In this study, the finding of anxiety levels in person working from home after using BAI indicates the role of COVID-19 pandemic lockdown. Professional, financial and personal life of male professionals was also affected during this period. It highlights the role \& importance of a healthy work culture, maintaining balance between personal and professional life. The policy makers should provide interventions to mitigate the effect of working from home. It also emphasizes the role of employer to promote and provide good mental health at all working spaces, flexible working hours and also to sensitize and counsel the mental health professionals to seek intervention.

\section{Limitations of this Study}

The limitation of our study was small sample size and how this lockdown affected women professionals working from home differently. It was a self-designed survey in which respondent had subjectively assessed how the lockdown had an impact on their personal, financial, and professional life. This may cause some respondent bias. Also, our study was entirely focused to know the anxiety levels in male professionals working from home during the COVID-19 pandemic and there could be a possibility of these professionals working from home suffering from other comorbid psychiatric conditions at the time of survey.

\section{Strength of this Study}

The strength of our study was that it provides evidence that male professionals working from home had increased anxiety level because of the COVID-19 lockdown. Recommendation we recommend study on a larger sample size and a comparative study on work from home and work from office.

\section{Recommendation}

We recommend study on larger sample size and a comparative study work from home and work from office.

Data sharing statement provided by the authors is available with the full text of this article at jemds.com.

Financial or other competing interests: None.

Disclosure forms provided by the authors are available with the full text of this article at jemds.com.

\section{REFERENCES}

[1] Hawryluck L, Gold WL, Robinson S, et al. SARS control and psychological effects of quarantine, Toronto, Canada. Emerg Infect Dis 2004;10(7):1206-12.

[2] Mental health and psychosocial considerations during the COVID-19 outbreak. 2020 https://www.who.int/publications/i/item/WHO-2019nCoV-MentalHealth-2020.1

[3] Loiwal M. 20\% increase in patients with mental illness since coronavirus outbreak: Survey. India Today 2021 https://www.indiatoday.in/india/story/20-per-centincrease-in-patients-with-mental-illness-sincecoronavirus-outbreak-survey-1661584-2020-03-31

[4] Nishiura H, Jung S, Linton NM, et al. The extent of transmission of novel coronavirus in Wuhan, China, 2020. Journal of Clinical Medicine 2020;9(2):330.

[5] Coronavirus cases: statistics and charts - worldometer. Srv1.worldometers.info. 2020. http://srv1.worldometers.info/coronavirus/coronavirus -cases/

[6] COVID-19 disrupting mental health services in most countries, WHO survey. Who.int. 2021 
https://www.who.int/news/item/05-10-2020-covid19-disrupting-mental-health-services-in-most-countrieswho-survey

[7] Mental health and COVID-19. Euro.who.int. 2021 https://www.euro.who.int/en/health-topics/healthemergencies/coronavirus-covid-19/publications-andtechnical-guidance/mental-health-and-covid-19

[8] Salari N, Hosseinian-Far A, Jalali R, et al. Prevalence of stress, anxiety, depression among the general population during the COVID-19 pandemic: a systematic review and meta-analysis. Global Health 2020;16(1):57.

[9] Qualtrics leading experience management \& survey software. Qualtrics 2020 https://www.qualtrics.com/uk/?rid=ip\&prevsite=en\&n ewsite $=$ uk\&geo=IT\&geomatch $=u k$

[10] Beck AT, Epstein N, Brown G, et al. An inventory for measuring clinical anxiety: psychometric properties. J Consult Clin Psychol 1988;56(6):893-7.

[11] Beck A, Steer R. Manual for the beck anxiety inventory. San Antonio, TX: Psychological Corporation 1990.

[12] Abramson A. How COVID-19 may increase domestic violence and child abuse. American Psychological Association, April $\quad 8,2020$. https://www.apa.org/topics/covid-19/domesticviolence-child-abuse

[13] Chandra J. Covid-19 lockdown | Rise in domestic violence, police apathy: NCW. The Hindu 2020.https://www.thehindu.com/news/national/covid- 19-lockdown-spike-in-domestic-violencesaysncw/article31238659.ece

[14] World Health Organization.COVID-19 and violence against women what the health sector/system can do World Health Organization2020. https://apps.who.int/iris/bitstream/handle/10665/331 699/WHO-SRH-20.04-eng.pdf?ua=1

[15] Balakrishnan R. How work from home is affecting women's mental health in times of coronavirus YourStory.com. 2021 https://yourstory.com/herstory/2020/10/worldmental-health-day-work-home-women

[16] Chen L, Zhao H, Razin D, et al. Anxiety levels during a second local COVID-19 pandemic breakout among quarantined people: a cross sectional survey in China. J Psychiatr Res 2021;135:37-46.

[17] COVID-19 disrupting mental health services in most countries, WHO survey [Internet]. Who.int. 2021 https://www.who.int/news/item/05-10-2020-covid19-disrupting-mental-health-services-in-most-countrieswho-survey

[18] Banerjee D. The COVID-19 outbreak: crucial role the psychiatrists can play. Asian J Psychiatr 2020;50:102014.

[19] Duan L, Zhu G. Psychological interventions for people affected by the COVID-19 epidemic. Lancet Psychiatry 2020;7(4):300-2. 